\title{
Experimental Study of the Effect of Misalignment on Rolling Element Bearing
}

\author{
Mohsin H. Albdery and Istvan Szabo
}

\begin{abstract}
Any single machine rotary component in the process could result in downtime costs. It is necessary to monitor the overall machine health while it is in use. Bearing failure is one of the primary causes of machine breakdown in industry at high and low speeds. A vibration signature evaluation has historically determined misalignments in shafting systems. These misalignments are also responsible for the bearing increase in temperature. The purpose of this work is to undertake a comparative study to obtain the reliability of the effect of the amount of misalignment on bearing by using thermography measurement. An experimental study was performed in this paper to indicate the existence of machine misalignment at an early stage by measuring the bearing temperature using a thermal imaging camera. The effects of load, velocity, and misalignment on the bearings and their temperature increase have been investigated. The test bench's rolling-element bearing is an NTN UCP213-208 pillow block bearing. It has been observed that by tracking the change of temperature in bearings could lead to misalignment detection and the effect of the amount of misalignment on it.
\end{abstract}

Keywords - misalignment, rolling element bearing, failure of bearing, asynchronous motor, thermography.

\section{INTRODUCTION}

The absence of alignment, or misalignment, is a situation where two or more machine shafts rotating centerlines are not in same centerline with each other. This is not easy to detect when the machine is running. The rotating device is aligned following a series of detailed steps of a few alignment techniques. It can be said that the purpose of alignment is to position the equipment in such a way that any deviation of the centerlines of the shaft is below the specified or required criterion. Furthermore, the objective is to minimize downtime of the equipment and to maximize the operating life of the rotating equipment [1]. The misalignment of rotating equipment may have many effects on the equipment and the entire system [2]. It can be seen from Fig. 1 that the larger the misalignment of the guideways, the more significant reduction in the time of continuous operation until failure.

Misalignment may lead to some other deficiencies, such as: premature failure of bearings, rapid wear of bearings due to induced mechanical heating effect, excessive leakage of seal lubricant, failure of couplings, etc. [3]. Shaft misalignment increases interactions with which the bearings must take in and damage seals, create looseness and allows

Submitted on November 10, 2021.

Published on December 02, 2021.

Mohsin H. Albdery, Mechanical Engineering Doctoral School, Hungarian University of Agriculture and Life Sciences MATE, Hungary.

(e-mail: mohsinalbdery@gmail.com) fluid and pollutants to penetrate the bearings. Aspects that must be considered are that energy consumption is increased, energy efficiency and economic effects are lessened. As shown in Fig.1 two main types of shaft misalignment are:

(I) Shaft parallel misalignment in which shaft centerlines are parallel (Fig. 1(a)).

(II) Shaft angular misalignment in which shaft centerlines intersect (Fig. 1(b)),

Misalignment typically leads to a higher load than the design specification of the bearing and can cause early fatigue failure [4]. The stresses applied directly below the loadbearing surfaces are caused by fatigue and are seen to spread the surface metal. Coupling results in the form of damage to the coupling, or friction-related extreme heat may signify the device being misaligned. Operational temperatures play an important role in the overall efficiency of the bearing system [5]. The loading temperature influences many important parameters such as the viscosity of the lubricant, carrying capability, load distribution and power loss.

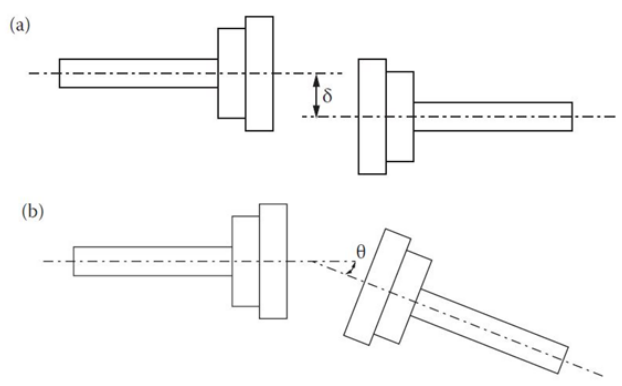

Fig. 1 Shaft misalignment: (a) parallel, (b) angular [3]

\section{EXPERIMENTAL PROCEDURES}

In this context, we will use an experimental measurement well adapted to the resolution of this problem, to estimate the probabilities-characteristics of the probable operating states of a bearing in misalignment state.

\section{A. Experimental Works for Bearing Diagnosis}

In the experimental works, a test bench capable of examining bearings was created in the Department of Machine and machinery in the Institute of Technology of MATE University (Fig. 2). An asynchronous motor is commonly used in many industrial applications, mainly pumps and fans [6]. Faults in positioning, bearing, and

Istvan Szabo, Institute of Technology, Hungarian University of Agriculture and Life Sciences MATE, Hungary.

(e-mail: Szabo.Istvan.prof@uni-mate.hu) 
coupling are common in these types of machines. Bearing used in the test bench is NTN UCP213-208, pillow block bearing.

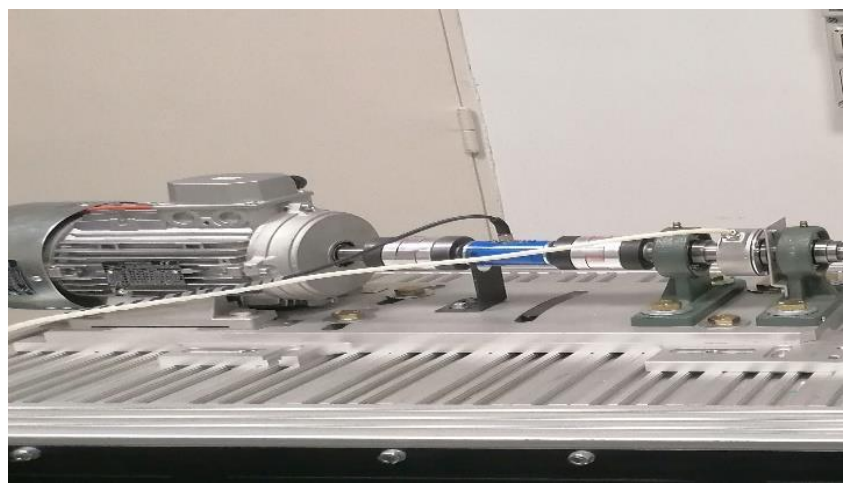

Fig. 2 Test bench of experimental work

\section{B. Alignment Procedure}

When the devices operate in a standard working state, the rotational centers of the shafts are collinear [6]. Alignment is the method of linking the moving machine's middle shafts to changing the relative location of two machines coupled, and then the device is a stationary machine. When the machines operate during regular operation, the middle line of the axis is concentrated. Determine and change the relative location of two devices, such as a motor and a pump, that are related. Using the Fixturlaser XA system, we can check the misalignment between correction of horizontal shaft alignment moving the front and the back pair of the motor's feet, vertically and horizontally shafts are aligned within the specified tolerances [7]. There is a tolerance table present in the device's manual is used for this purpose. The Fixturlaser XA system has two measuring units placed on each shaft by using the fixtures supplied with the system, as shown in Fig. 3. After rotating the shafts into different measuring positions with bearing, the system calculates the two shafts' relative distance in two planes. The distances between the bearing to the coupling and the distances to the motor feet are entered into the system. The Fixturlaser XA display then shows the actual alignment condition together with the position of the motor. It is possible to explicitly change the machine according to the displayed values. The alignment results saved to the memory manager. For more documentation purposes, the data in the memory manager can conveniently be moved to a PC.

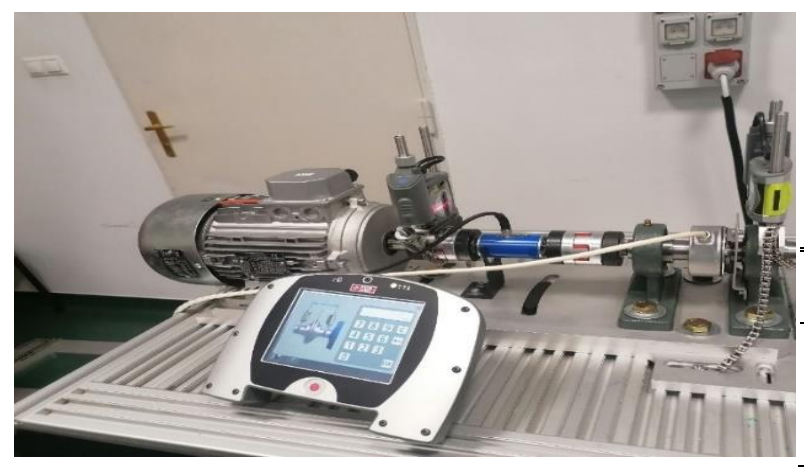

Fig. 3. Using Fixturlaser XA system to check the asynchronous motor alignment.

\section{Thermography Measurement}

The NEC thermal imaging camera conducts measurements related to temperature variations in the bearings (Fig. 4). The asynchronous motor's rotation speed is 2000 RPM, and the measurement will be after 10 minutes from the beginning of the operation. The images are processed with the camera's software, Image Processor Pro II, and then the data will be analyzed. The measurements of the temperature change are taken while for three different states which is $0.05 \mathrm{~mm}, 0.010$ $\mathrm{mm}$ and $0.25 \mathrm{~mm}$. Using Fixturlaser XA, it is possible to adjust these conditions with using Fixturlaser shims after completely adjusting asynchronous motor alignment. Before starting thermal camera software, we remove one of these shims from two sides of the asynchronous motor to check each state's temperature change.

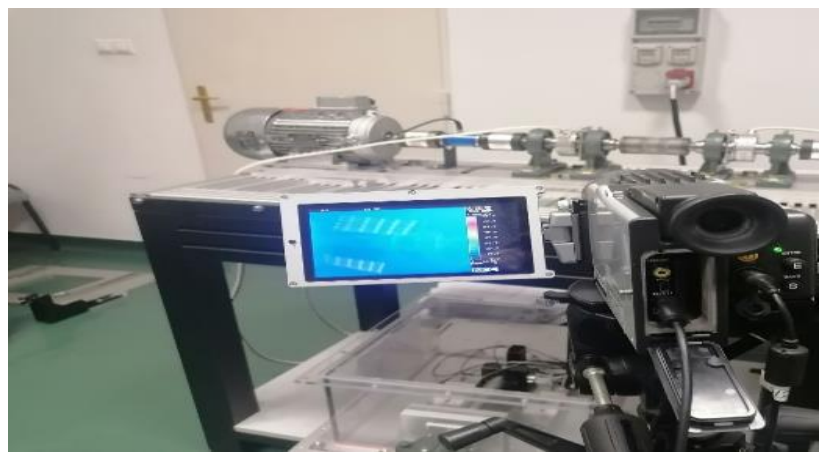

Fig. 4. NEC thermal imaging camera.

\section{RESULTS AND DISCUSSION}

Misalignment contributes to a rise in friction forces within the bearing's elements of the experiment, leading to a rise in the bearing's temperature. However, through thermography monitoring, the effect of the misalignment in the bearings can be detected relatively easily. In this part we will present only thermography data which got in the experimental test. Due to excessive heat generated at the bearings, the remainder of the grease can become baked, and form hard particles as shown in Fig.5, Fig 6, Fig 7 and Fig 8. These particles score the bearing races, which leads to further deterioration of the bearing. To extend the life of the bearings, the temperatures of rolling element bearings are not allowed to rise above $125^{\circ} \mathrm{C}$. From table 1 we can find that, if the asynchronous motor has smaller misalignment this can make smaller raise in temperature during work operating of the machine in the bearing but if the alignment more than 0.10 this cause bearing defect due to thermal growth in the bearing parts like in inner race or bearing element which increase the friction and it may defect the bearing.

TABLE I: THE COMPARISON BETWEEN 4 STATES OF MiSALIGNMENT (IMAGE PROCESSOR PRO II)

\begin{tabular}{ccccc}
\hline \hline Bearing & $\begin{array}{c}\text { Alignment } \\
\text { state }\end{array}$ & $\begin{array}{c}\text { Misalignment } \\
0.05\end{array}$ & $\begin{array}{c}\text { Misalignment } \\
0.10\end{array}$ & $\begin{array}{c}\text { Misalignment } \\
0.25\end{array}$ \\
\hline $\begin{array}{c}\text { Max Temp. at } \\
\text { Bearing 1 }\end{array}$ & $48.9 \mathrm{C}^{\circ}$ & $58.1 \mathrm{C}^{\circ}$ & $63.2 \mathrm{C}^{\circ}$ & $66.0 \mathrm{C}^{\circ}$ \\
$\begin{array}{c}\text { Max Temp. at } \\
\text { Bearing 2 }\end{array}$ & $48.6 \mathrm{C}^{\circ}$ & $56.6 \mathrm{C}^{\circ}$ & $61.9 \mathrm{C}^{\circ}$ & $64.1 \mathrm{C}^{\circ}$ \\
\hline \hline
\end{tabular}




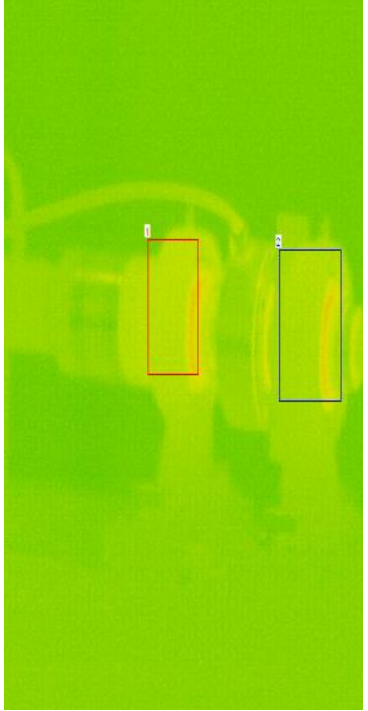

Fig. 5. Bearings in alignment state.

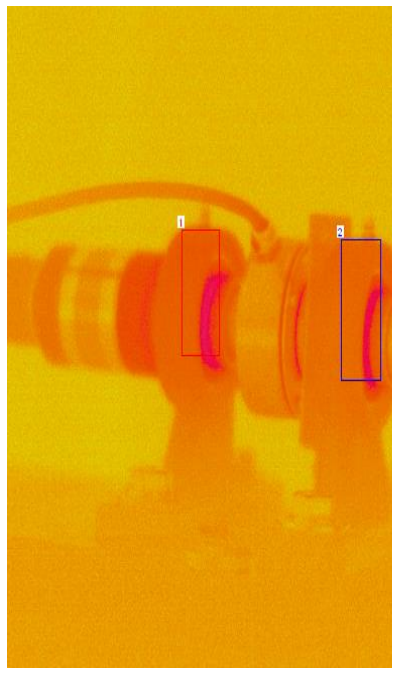

Fig. 7. Bearings in misalignment $(0.1 \mathrm{~mm})$.

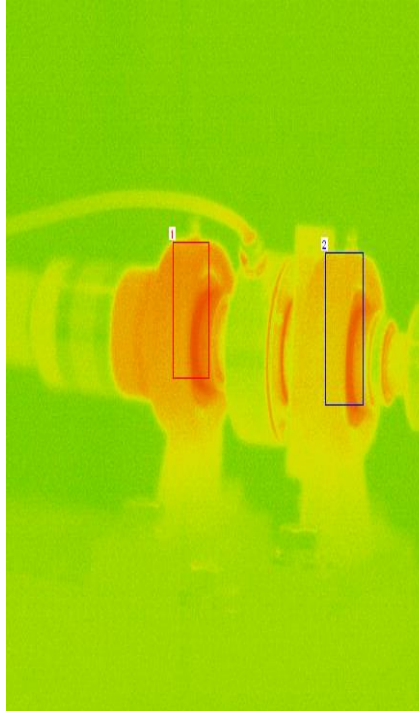

Fig. 6. Bearings in misalignment $(0.05 \mathrm{~mm})$

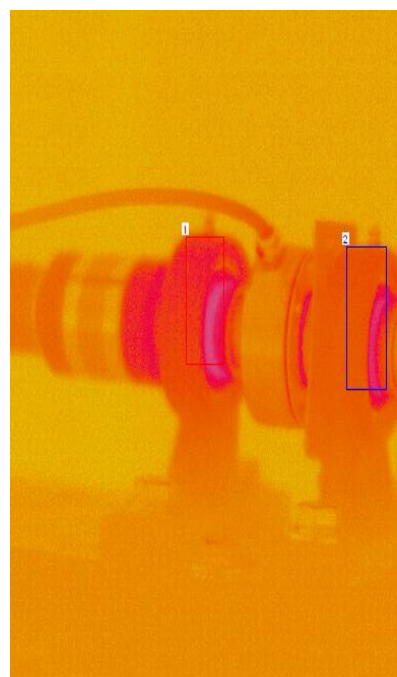

Fig. 8. Bearings in misalignment with $(0.25 \mathrm{~mm})$
The influence of the misalignment can be noted when an increase in the amount of the misalignment on the non-drive end bearings is more than the effect on drive end bearing and coupling. The thermal images are shown in Fig. 5. Bearings in alignment state and maximum temperature measured was $48.9{ }^{\circ} \mathrm{C}$ at bearing 1 and $48.6{ }^{\circ} \mathrm{C}$ at bearing 2 . The thermal images are shown in Fig. 6 bearings in misalignment (0.05) $\mathrm{mm}$ and the maximum temperature measured was $58.1^{\circ} \mathrm{C}$ at bearing 1 and $56.6{ }^{\circ} \mathrm{C}$ at bearing 2 . After measuring the temperature in misalignment with $(0.1 \mathrm{~mm})$ and $(0.25 \mathrm{~mm})$ indicated the temperature raise with increasing angular misalignment in the motor. As the misalignment develops, the temperature increases due to increased friction. Fig. 7 shows that the temperature of the bearing has started to increase. In Fig. 8 indicates that the temperatures have increased to be higher as the load has risen. The bearing housing is also affected by the heat energy generated from misalignment and even the shaft coupling is affected. All this heat energy reaches the bearings and subsequently to the lubricant. The resultant force accelerates the wear of the bearing. Leave unchecked, and this problem will first cause the bearing to wear, followed by the seal and eventually the coupling [8]
Due to an increase in the load on the bearing element, the bearing's components undergo deflection along with an increase in frictional torques. The heat generated at the bearings thus increases, which is responsible for the rise in temperature at the bearings. In Fig. 9 we can see how the change of temperature during operating condition is related to the increase in the asynchronous motor's misalignment in the test bench. Also, it appears the bearing 1temperature is higher than bearing 2 because it is connected to the shaft and coupling directly after asynchronous motor, which gave a lower change in temperature in the bearing 2 .

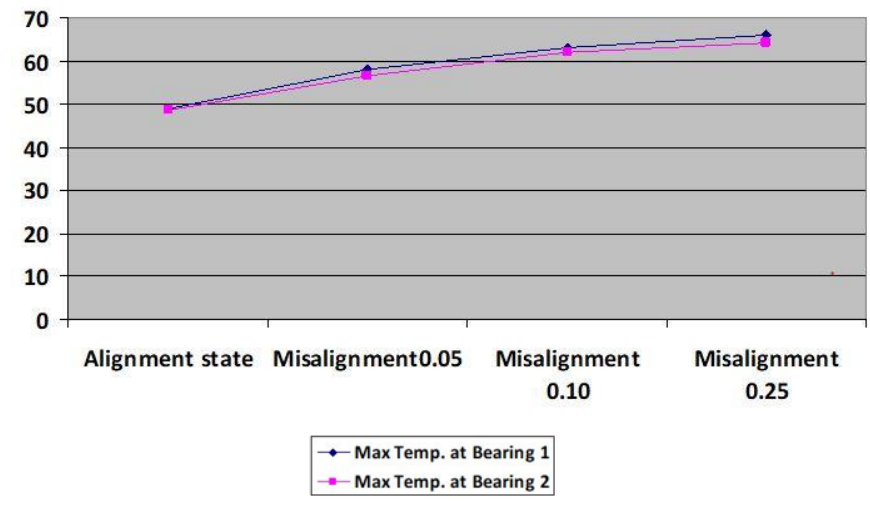

Fig. 9 Graph of relationship between misalignment and temperature for bearings.

\section{CONCLUSION}

In this article, experimental work has been done using the test bench developed by at the department of machine and machinery in the Institute of Technology of MATE university, through laboratory experiments, can help to measure different failure mode of bearing conditions and can be tested, the result of which is indispensable in the temperature, vibration Leads to failure of machine elements The test equipment is suitable for testing the operation, lifetime, and efficiency of bearing and other rotating machine elements. The asynchronous motors are used widely in the industrial sector operating under the mentioned conditions. The result showed the effect of misalignment of asynchronous motors on bearings. The importance of study of the thermography of bearing is to avoid failure due to thermal expansion which increases the fraction force and defects the bearing surface like in ball bearing or roller bearing.

\section{ACKNOWLEDGMENT}

This work was supported by the Stipendium Hungaricum Scholarship Programme, Institute of Technology and the Mechanical Engineering Doctoral School, Hungarian University of Agriculture and Life Sciences, Gödöllö, Hungary.

\section{REFERENCES}

[1] Malla C, Panigrahi I. Review of condition monitoring of rolling element bearing using vibration analysis and other techniques. Journal of Vibration Engineering \& Technologies. 2019 Aug;7(4):407-14. 
[2] Verma AK, Sarangi S, Kolekar MH. Experimental investigation of misalignment effects on rotor shaft vibration and on stator current signature. Journal of Failure Analysis and Prevention. 2014 Apr;14(2):125-38.

[3] YILMAZ Ö, Aksoy M, Kesilmiş Z. Misalignment fault detection by wavelet analysis of vibration signals. International Advanced Researches and Engineering Journal. 2019;3(3):156-63.

[4] Fatima S, Mohanty AR, Naikan VA. A misalignment detection methodology by measuring rate of temperature rise of shaft coupling using thermal imaging. Proceedings of the Institution of Mechanical Engineers, Part O: Journal of Risk and Reliability. 2015 Jun;229(3):209-19.

[5] Nabhan A, Ghazaly N, Samy A, Mousa MO. Bearing fault detection techniques-a review. Turkish Journal of Engineering, Sciences and Technology. 2015 Jan;3(2).

[6] Gárdonyi P, Nagy D, Gergely Z and Bercesi G. Developing test equipment suitable for testing torque transfer systems used in agriculture. Poljoprivredna tehnika. 201742 27-36.

[7] Gupta P, Pradhan MK. Fault detection analysis in rolling element bearing: A review. Materials Today: Proceedings. 2017 Jan 1;4(2):2085-94.

[8] Ali JB, Chebel-Morello B, Saidi L, Malinowski S, Fnaiech F. Accurate bearing remaining useful life prediction based on Weibull distribution and artificial neural network. Mechanical Systems and Signal Processing. 2015 May 1;56:150-72. 